\title{
Evolution under different storage conditions of anomalous blue coloration of Mozzarella cheese intentionally contaminated with a pigment-producing strain of Pseudomonas fluorescens
}

\author{
B. T. Cenci-Goga, ${ }^{1}$ M. Karama, ${ }^{2}$ P. Sechi, M. F. lulietto, S. Novelli, and S. Mattei \\ Dipartimento di Medicina Veterinaria, Laboratorio di Ispezione degli Alimenti di Origine Animale, Università degli Studi di Perugia, 06126 Perugia, \\ Italy
}

\begin{abstract}
Several widespread occurrences of anomalous blue coloration of Mozzarella cheese have been recorded in the United States and some European countries. Official laboratory analysis and health authorities have linked the occurrences to contamination of the processing water with strains of Pseudomonas fluorescens, although several experts questioned how to unequivocally link the blue color to the presence of the microorganism. To establish a method to determine whether a given Pseudomonas spp. strain is responsible for the defect and study the evolution of the coloration under different storage conditions, we developed an in vitro system for the evaluation of blue coloration of Mozzarella cheese intentionally contaminated with strains of $P$. fluorescens. The purpose of the system was to determine whether $P$. fluorescens strains, isolated from Mozzarella cheese with anomalous blue coloration, were able to reproduce the blue coloration under controlled experimental conditions. Thirty-six trials of experimental inoculation of Mozzarella cheese in different preservation liquids were conducted using various suspensions of $P$. fluorescens (P. fluorescens ATCC 13525, P. fluorescens CFBP 3150, and $P$. fluorescens 349 field strain isolated from blue-colored Mozzarella cheese) at different concentrations and incubated at different temperatures. Growth curves of all tested $P$. fluorescens strains demonstrated that after $3 \mathrm{~d}$ of incubation the concentration was generally $>10^{6} \mathrm{cfu} / \mathrm{g}$ of Mozzarella cheese incubated in either tryptic soy broth (control) or conditioning brine. Prolonged incubation for $5 \mathrm{~d}$ at either $20^{\circ} \mathrm{C}$ or $8^{\circ} \mathrm{C}$ led to concentrations up to $10^{9} \mathrm{cfu} / \mathrm{g}$ of Mozzarella cheese incubated in tryptic soy broth and up to $10^{8} \mathrm{cfu} / \mathrm{g}$ of Mozzarella cheese incubated in preservation liquid. All Mozzarella cheeses inoculated with the field strain of $P$.
\end{abstract}

\footnotetext{
Received July 13, 2014.

Accepted August 1, 2014

${ }^{1}$ Corresponding author: beniamino.cencigoga@unipg.it

${ }^{2}$ Present address: University of Pretoria, Faculty of Veterinary Science, Department of Paraclinical Sciences, Onderstepoort, South Africa.
}

fluorescens, except those opened $1 \mathrm{~h}$ after packaging and stored at $8^{\circ} \mathrm{C}$, showed the characteristic anomalous blue coloration, which appeared from 1 to $72 \mathrm{~h}$ after opening the packaging, and was proportional to colony count, duration of storage, and storage temperature. With the proposed system, which enabled a larger number of samples to be analyzed under controlled experimental conditions and a large amount of data to be generated in a short time, we described precisely how and under which conditions the presence of $P$. fluorescens in Mozzarella cheese is responsible for the anomalous blue coloration. The system will help producers intercept contaminated batches and help consumers avoid the conditions under which the defect can appear.

Key words: Pseudomonas spp., Mozzarella cheese, blue coloring, conditioning brine

\section{INTRODUCTION}

Several microorganisms can produce pigments in food. In refrigerated meat, psychrotrophic bacteria such as Acinetobacter spp., Moraxella spp., and Pseudomonas spp. can produce off-odors and anomalous gray-brown discoloration. Pseudomonas phosphorescens causes fluorescent areas in pig and bovine meat. In dairy products, possible contaminants are Pseudomonas synxantha, which can give to milk a yellowish color, or Pseudomonas syncyanea, which is responsible for blue pigmentation of refrigerated milk, and Serratia marcescens, which creates red areas in cheeses (Cenci-Goga et al., 1993, 1995; Cantoni et al., 2000, 2001; Kobayashi et al., 2007; Diez et al., 2009; Sechi et al., 2011). In summer 2010, several occurrences of anomalous coloration of Mozzarella cheese produced in Europe and the United States were described (https://webgate.ec.europa.eu/ rasff-window). Official analyses linked the blue coloring to contamination of Mozzarella cheese with strains of Pseudomonas fluorescens, which derived mainly from water used during the processing. However, alerts for high levels of $P$. fluorescens and occurrences of anomalous coloration are not consistent, because only some strains are able to produce the pigment and because an 
association of storage conditions, temperature abuse, and improper handling after purchase is essential for the blue color defect to appear.

To investigate the link between (1) contamination of Mozzarella cheese with $P$. fluorescens, (2) anomalous coloration, (3) storage temperature, and (4) further handling by consumers, we set up a method to determine whether a given Pseudomonas spp. strain was responsible for the defect and to study the evolution of the coloration under different storage and handling conditions.

\section{MATERIALS AND METHODS}

Throughout the experiment, we simulated the following actual conditions: (1) contamination of the preservation liquid of Mozzarella cheese with different strains of Pseudomonas spp., (2) storage conditions after packaging (refrigeration conditions or thermal abuse), and (3) handling conditions after purchase by the consumer (refrigeration conditions or thermal abuse).

\section{Mozzarella Cheese Production}

Three batches of custom-made Mozzarella cheeses (2 $\mathrm{cm}$ in diameter, $10 \mathrm{~g}$ each) were produced in a local dairy plant, according to the usual procedure (Coppola et al., 1988, 1990). Briefly, Mozzarella cheese was made from whole raw milk by adding a natural whey culture from the previous day's manufacture as starter. Raw milk was heated to $37^{\circ} \mathrm{C}$ and rennet (liquid calf rennet, titer: 1:10,000) and natural whey culture were added. After a curd-ripening phase $\left(4-5 \mathrm{~h}\right.$ at $\left.35-37^{\circ} \mathrm{C}\right)$, which occurred under whey, the optimal $\mathrm{pH}(4.9-5.1)$ was reached and the drained curd was stretched in hot water $\left(90-95^{\circ} \mathrm{C}\right)$. The elastic product formed was then hand-molded to obtain the typical round shape with a hand-cut on one side, which gives it the name Mozzarella (from the Italian "mozzare" for hand-cutting), and hardened in cold water. Mozzarella was then salted in brine $(20 \% \mathrm{NaCl}$, wt/vol, for $5 \mathrm{~min})$, packaged in plastic bags, and immediately stored under the experimental conditions. At any given sampling time, plastic bags were transported to the laboratory in refrigerated boxes at $4^{\circ} \mathrm{C}$ and analyzed within $2 \mathrm{~h}$.

\section{Bacterial Strains and Contamination of Mozzarella Cheese}

Three replications (one per Mozzarella cheese batch) were done. For each replication, Mozzarella cheeses were put into 2 different preservation liquids: (1) conditioning brine (CB; "acqua di filature" - the water used in the stretching process, added with $0.2 \% \mathrm{NaCl}$, and $0.05 \%$ lactic acid, $\mathrm{pH} 4$ ) to mimic the actual preservation liquid used for Mozzarella cheeses sold in the market, and (2) tryptic soy broth (TSB, Oxoid, Basingstoke, UK) as control, and stored at $8^{\circ} \mathrm{C}$ and at $20^{\circ} \mathrm{C}$ to mimic actual and temperature abused shelf conditions (Cenci Goga et al., 2002). Both preservation liquids were contaminated with P. fluorescens ATCC 13525 (PSF ATCC), P. fluorescens CFBP 3150 (PSF CFBP), and P. fluorescens field strain (PSF 349) to achieve the following final concentrations: 0 (control), 10 , and $10^{3} \mathrm{cfu} / \mathrm{mL}$. For each combination of preservation liquid, strain, and bacterial concentration, a locking plastic food storage container was filled with a redundant number (i.e., more than the exact number needed) of Mozzarella cheeses for further analysis and observations.

\section{Evolution of Pseudomonas spp. and Culture Media}

Triplicate samples of preservation liquid and Mozzarella cheese per combination at d 1,3 , and 5 were plated onto the following culture media for Pseudomonas spp.: King A (King et al., 1954), King B (King et al., 1954), Pseudomonas agar base with CN (cetrimide-nalidixic acid) selective supplement (Oxoid, Basingstoke, UK), Pseudomonas agar base with CFC (cephalothin-sodium fusidate-cetrimide) selective supplement (Oxoid), and Luria peptone glucose agar (yeast extract, 7 g; bacto peptone, $7 \mathrm{~g}$; glucose, $7 \mathrm{~g}$; agar-agar, $15 \mathrm{~g} ; \mathrm{H}_{2} \mathrm{O}, 1,000$ $\mathrm{mL}, \mathrm{pH}$ 7.2). About $30 \mathrm{~g}$ of sample (3 Mozzarella cheeses) per replication was transferred aseptically to $225 \mathrm{~mL}$ of sterile buffered peptone water (Oxoid) and homogenized in a stomacher (PBI International, Milan, Italy) for 1 min at low speed and 1 min at high speed at room temperature. Serial decimal dilutions in buffered peptone water were prepared, and triplicate 1- or 0.1-mL samples of appropriate dilutions were poured or spread on agar plates and incubated at $20^{\circ} \mathrm{C}$ for 24 to $72 \mathrm{~h}$. Sensitivity for spread plates was $10^{2} \mathrm{cfu} / \mathrm{g}$ and for pour plates was $10 \mathrm{cfu} / \mathrm{g}$, and the $95 \%$ confidence limit, as given by the classic formula $2 \mathrm{~s}=2 \sqrt{ } \mathrm{x}$, where $\mathrm{s}=$ standard deviation and $\mathrm{x}=$ variance (Adams and Moss, 2000), ranged between $\pm 37 \%$ and $\pm 12 \%$ (i.e., plates with counts ranging from 30 to 300). Therefore, no plates with $<30$ cfu were used for data analysis, and when this applied to the lowest dilution, the results were recorded as $<300$ for pour plates and $<3,000$ for spread plates.

\section{Evaluation of Blue Coloration}

At $0,1,6,12,24,72$, and 192 h, 3 Mozzarella cheeses per food storage container contaminated with the bluegenic P. fluorescens field strain (PSF 349) were removed from the container and placed into another 
container without any liquid (to mimic the behavior of a consumer who opens the box, removes the Mozzarella cheese from the original packaging, and stores it in air) at $8^{\circ} \mathrm{C}$ (to mimic the average temperature of an household refrigerator) or at $20^{\circ} \mathrm{C}$ (to mimic temperature abuse conditions at home; i.e., food prepared and left at room temperature before dinner) and observed every other hour until the appearance of the blue coloration, if any. To minimize the variability of interpretation, the same researcher carried out the whole observation round, and a series of photographs was taken to correctly evaluate any color change. A Nikon D200 digital camera connected to a Nikon Speedlight SB-800 and in a set up consisting of 5 Nikon wireless remote speedlight SB-R200, in full through-the-lens (TTL) automatism, with an AF Nikkor 35mm f/2D lens was used (Nikon, Tokyo, Japan). Cheeses were placed in a specific dark cabinet for professional macrophotography, and a semitranslucent, light-diffusing plastic tool was placed in front of the light-emitting source of the flash to evenly distribute light and to reduce shading or shadowing. A light gray background was placed behind the cheese. Visual observation and examination of digital photographs were done on an Apple Cinema HD Display 23-inches $(1,980 \times 1,200 \mathrm{dpi}$; Apple Inc., Cupertino, CA) at its maximum brightness of $400 \mathrm{~cd} / \mathrm{m}^{2}$, contrast ratio of 700:1, pixel pitch $0.258 \mathrm{~mm}$, and pixel density of 98.44 ppi. For each observation, an objective measurement of each Mozzarella cheese was made with a Minolta Chroma Meter CR-300 colorimeter (Minolta Co. Ltd., Osaka, Japan) with an 11-mm-diameter aperture, D65 illuminant, calibrated against a white tile. Color measurements [Commission internationale de l'éclairage (CIE) $L^{*}, a^{*}$, and $b^{*}$ values representing lightness, redness, and yellowness, respectively] were taken just before the digital photograph. For each sample, measurements of $\mathrm{L}^{*}, \mathrm{a}^{*}$, and $\mathrm{b}^{*}$ were taken on 3 adjacent locations and the arithmetic mean recorded.

\section{Analysis of Results}

For each sampling, the arithmetic means of the 3 subsamples and of the different culture medium of each of the 3 replication was calculated and then all the values (converted to log) were analyzed using GraphPad InStat, version 3.0b for Mac OS X (GraphPad Software Inc., San Diego, CA), and figures were obtained with GraphPad Prism version 6.0 for Mac OS X.

\section{RESULTS}

\section{Evolution of Pseudomonas fluorescens Strains}

Figure 1 shows the evolution of the 3 strains in artificially contaminated TSB (panels $\mathrm{a}, \mathrm{b}$, and c) and CB (panels $\mathrm{d}$, e, and f) and kept at $20^{\circ} \mathrm{C}$ (i.e., temperature abuse). Figure 2 shows the same conditions for proper storage conditions $\left(8^{\circ} \mathrm{C}\right)$. Figure 3 shows the evolution of the 3 strains in Mozzarella cheese in artificially contaminated TSB (panels a, b, and c) and CB (panels d, e, and $\mathrm{f}$ ) and kept at $20^{\circ} \mathrm{C}$ (i.e., temperature abuse); Figure 4 shows the same conditions for proper storage conditions $\left(8^{\circ} \mathrm{C}\right)$.

In control packaging (TSB used as preservation liquid), all tested strains reached a concentration $>10^{5}$ $\mathrm{cfu} / \mathrm{mL}$ after $1 \mathrm{~d}$ of storage at $20^{\circ} \mathrm{C}$ and $>10^{7} \mathrm{cfu} / \mathrm{mL}$ after 3 and $5 \mathrm{~d}$ of storage (Figure $1 \mathrm{a}, \mathrm{b}$, and c). In packaging made with $\mathrm{CB}$ and stored at $20^{\circ} \mathrm{C}$, the concentration was $>10^{4} \mathrm{cfu} / \mathrm{mL}$ for all strains only after $5 \mathrm{~d}$ of storage, but counts of PSF CFBP and PSF 349 were $>10^{5} \mathrm{cfu} / \mathrm{mL}$ after $3 \mathrm{~d}$ (Figures $1 \mathrm{~d}$, e, and f). Similar behavior was observed when all packaging (with either TSB or $\mathrm{CB}$ as preservation liquid) were stored under refrigeration $\left(8^{\circ} \mathrm{C}\right)$, with concentrations $>10^{6} \mathrm{cfu} / \mathrm{mL}$ after $5 \mathrm{~d}$ of storage and $>10^{4} \mathrm{cfu} / \mathrm{mL}$ after $3 \mathrm{~d}$, except for PSF ATCC, which reached $2.73 \log \mathrm{cfu} / \mathrm{mL}$ at $\mathrm{d} 3$ after initial contamination of $10 \mathrm{cfu} / \mathrm{mL}$ (Figure 2).

Analysis of Mozzarella cheese stored at $20^{\circ} \mathrm{C}$ in TSB showed concentrations higher than or very close to $10^{6}$ $\mathrm{cfu} / \mathrm{g}$ after only $1 \mathrm{~d}$ of storage (Figure $3 \mathrm{a}, \mathrm{b}$, and c); when stored in CB, Mozzarella cheese reached contamination levels $>10^{5} \mathrm{cfu} / \mathrm{g}$ on $\mathrm{d} 3$ (Figures $3 \mathrm{~d}$, e, and $\mathrm{f}$ ). For all Mozzarella cheese stored at $8^{\circ} \mathrm{C}$, the contamination of the food matrix exceeded $10^{4} \mathrm{cfu} / \mathrm{g}$ at $\mathrm{d} 3$ and was higher than or very close to $10^{4} \mathrm{cfu} / \mathrm{g}$ for packaging in both TSB and CB (Figure 4).

\section{Evaluation of Blue Coloration}

The observer was able to record very early appearance of blue coloring when the measured values (SD in parentheses) were $\mathrm{L}^{*}=70.95(1.23), \mathrm{a}^{*}=-0.40(0.50)$, and $\mathrm{b}^{*}=-2.46(0.60)$. For the full blue color, the measured values for $\mathrm{L}^{*}, \mathrm{a}^{*}$, and $\mathrm{b}^{*}$ were, respectively, 30.38 (1.34), 2.93 (2.28), and -30.49 (4.12). For control white cheese, corresponding values were 70.51 (5.71), 0.61 (0.11), and 1.37 (3.57). With prolonged storage, especially at $20^{\circ} \mathrm{C}$, the appearance of Mozzarella stored in TSB changed rapidly to a blue to bluish-brownish color.

Direct visual observation of Mozzarella cheese and examination of digital photographs on an Apple Cinema HD Display $(1,980 \times 1,200 \mathrm{dpi})$ were fully consistent. Figures 5 and 6 show, on the abscissa, the time (hours) needed for the blue coloring to appear on the surface of the Mozzarella cheese after opening the package (the time of opening the package is listed on the ordinate). Figure 5 shows the results for the control (i.e., Mozzarella cheese stored in TSB), and Figure 6 shows the results for Mozzarella cheese stored in CB. 

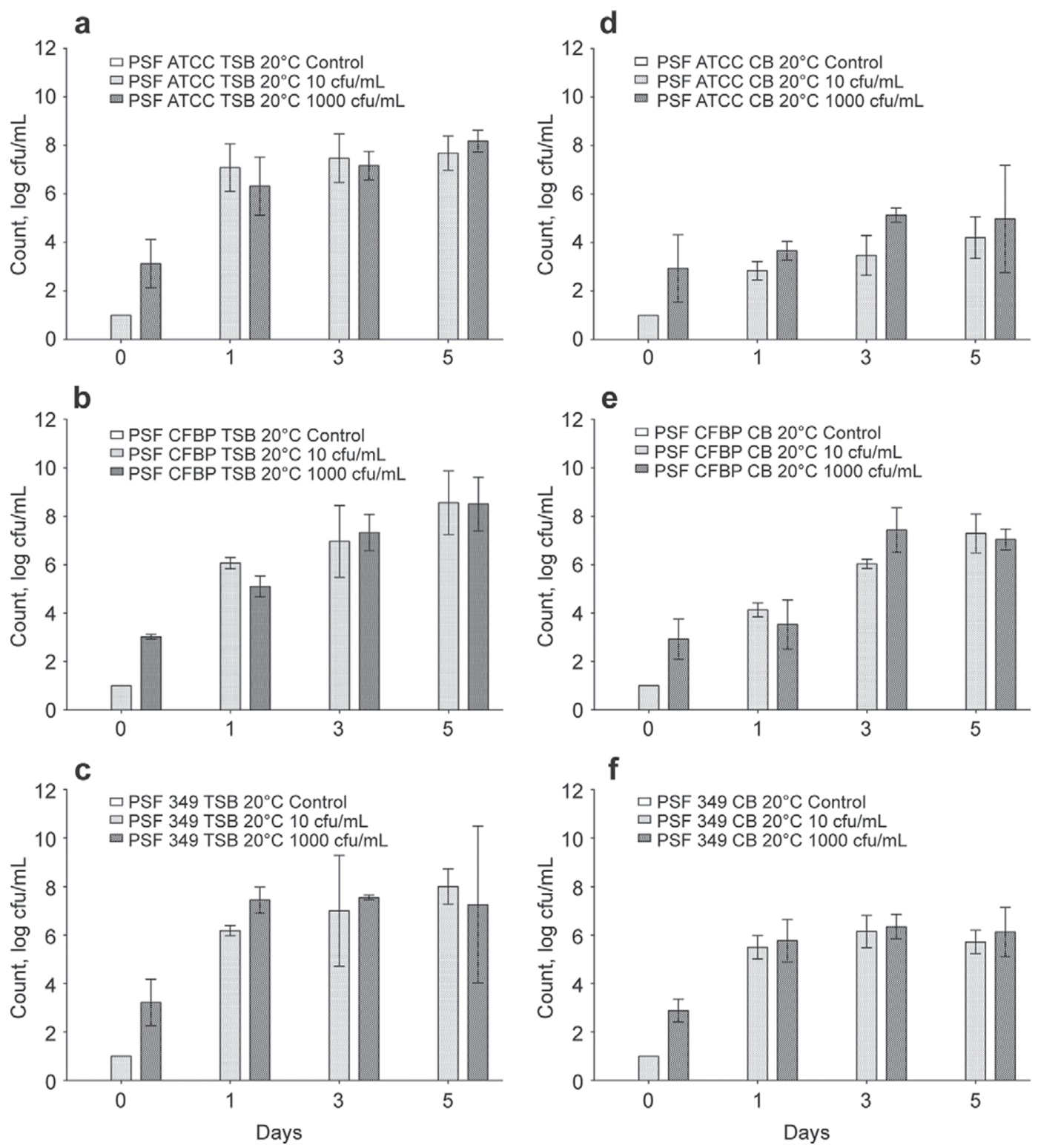

Figure 1. Evolution of Pseudomonas fluorescens strains ATCC 13525 (PSF ATCC), CFBP 3150 (PSF CFPB), and field strain 349 (PSF 349 ) in tryptic soy broth (TSB; panels a, b, and c) or conditioning brine (CB; panels $\mathrm{d}$, e, and f) artificially contaminated with 10 or $1,000 \mathrm{cfu} / \mathrm{mL}$ and kept at $20^{\circ} \mathrm{C}$ (i.e., temperature abuse).

Mozzarella cheeses packaged with TSB and removed after $1 \mathrm{~h}$ from packaging showed the blue coloring from $72 \mathrm{~h}$ (for cheeses stored at $8^{\circ} \mathrm{C}$ after packaging and left at $8^{\circ} \mathrm{C}$ after opening the packaging) to $12 \mathrm{~h}$ (for $20^{\circ} \mathrm{C}$ storage and $20^{\circ} \mathrm{C}$ after opening the packaging). With prolonged storage, especially at $20^{\circ} \mathrm{C}$, the appearance of Mozzarella stored in TSB changed rapidly, and after $72 \mathrm{~h}$, the liquid for all packaging contaminated with $1,000 \mathrm{cfu} / \mathrm{mL}$ showed a blue to bluish-brownish coloring (Figure 5).

For Mozzarella cheese in $\mathrm{CB}$ and stored at $20^{\circ} \mathrm{C}$, blue coloration of the liquid appeared after $192 \mathrm{~h}$ of storage for unopened packages. For packaging opened earlier, blue coloration appeared from $48 \mathrm{~h}$ (for packages contaminated with $10 \mathrm{cfu} / \mathrm{mL}$ and opened after $1 \mathrm{~h}$ from packaging) to $1 \mathrm{~h}$ (for packages contaminated with 10 or $1,000 \mathrm{cfu} / \mathrm{mL}$ and opened after $72 \mathrm{~h}$ from packaging) after opening the package (Figure 6a). Figure 6b shows the behavior of Mozzarella cheese opened after storage at $20^{\circ} \mathrm{C}$ but then kept at $8^{\circ} \mathrm{C}$. For Mozzarella cheese packages opened after only $1 \mathrm{~h}$ of temperature abuse, the blue coloring did not appear when the initial contamination was $10 \mathrm{cfu} / \mathrm{mL}$, whereas for the other combinations, the blue coloring appeared from 48 to 6 

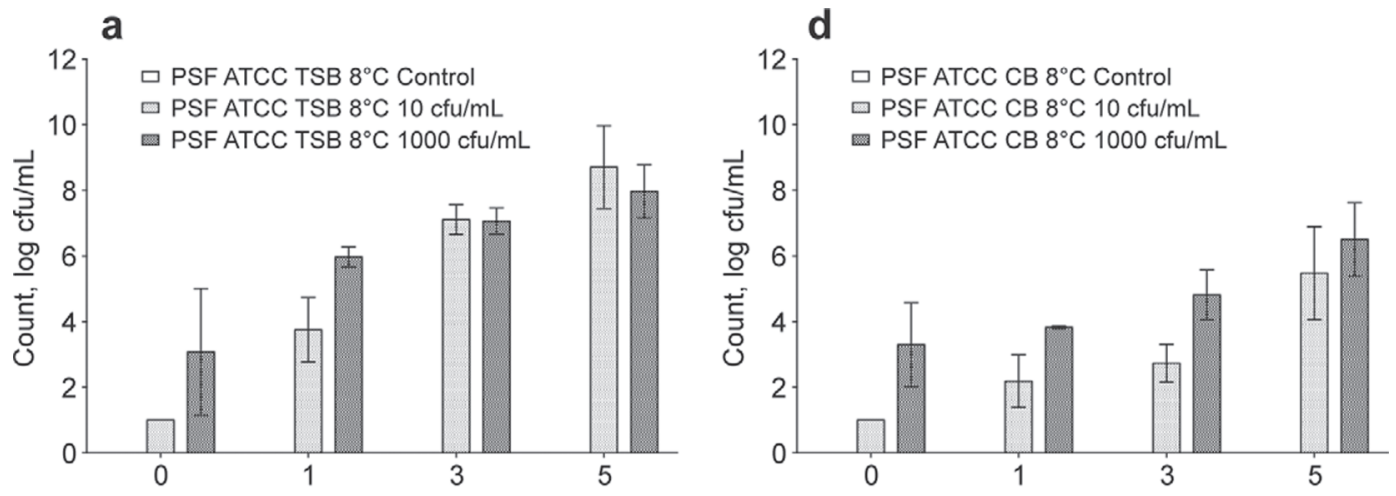

b
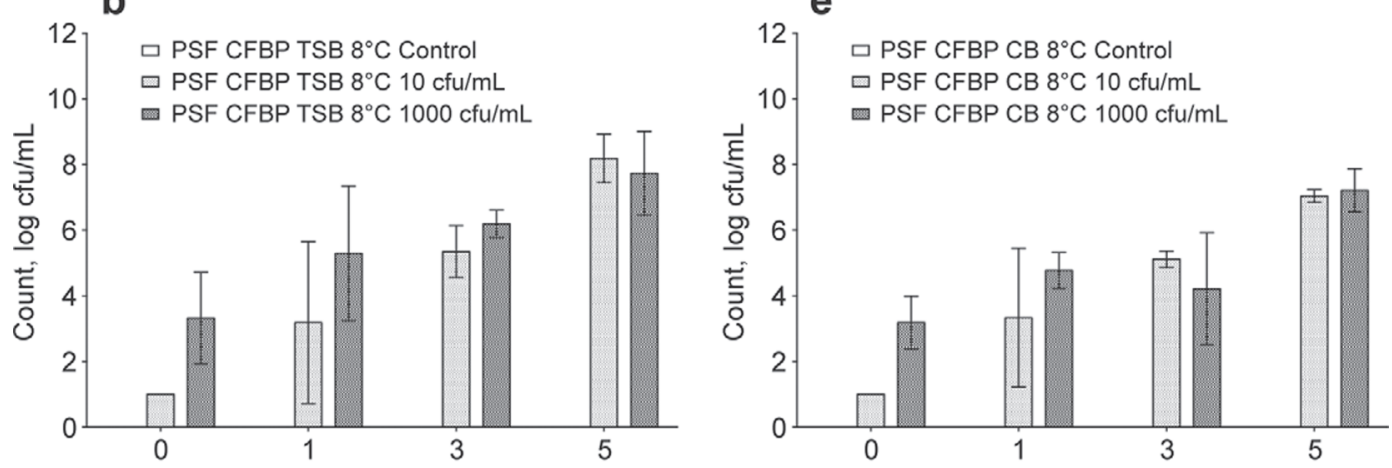

C
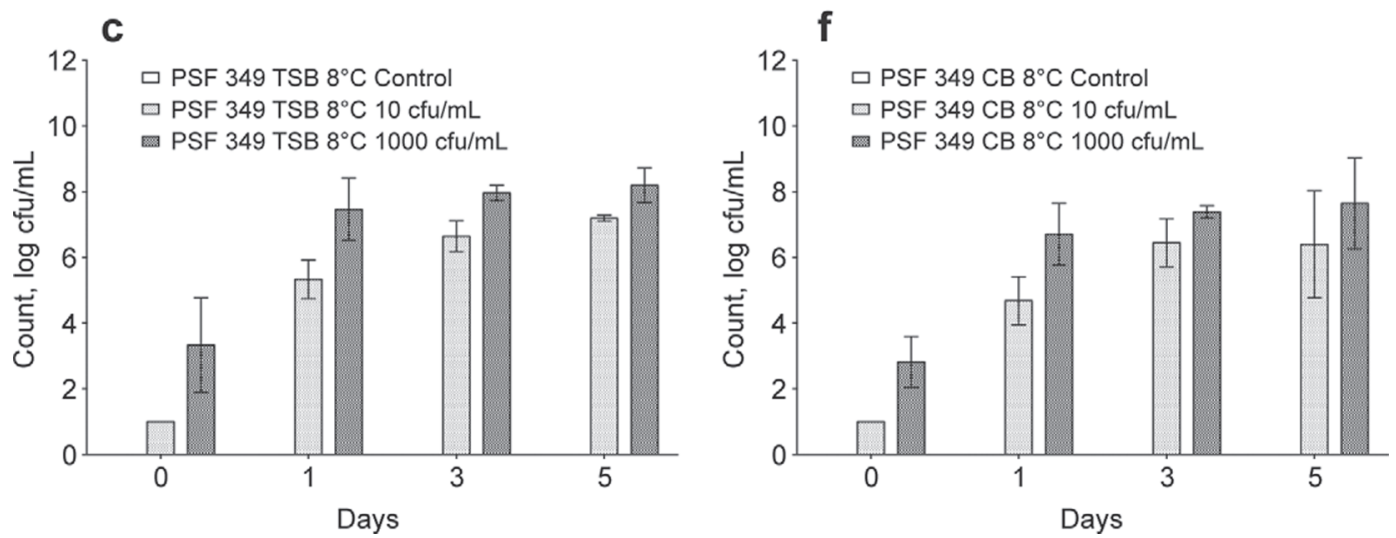

Figure 2. Evolution of Pseudomonas fluorescens strains ATCC 13525 (PSF ATCC), CFBP 3150 (PSF CFPB), and field strain 349 (PSF 349 ) in in tryptic soy broth (TSB; panels a, b, and c) or conditioning brine (CB; panels d, e, and f) artificially contaminated with 10 or 1,000 $\mathrm{cfu} / \mathrm{mL}$ and kept at $8^{\circ} \mathrm{C}$ (i.e., proper storage conditions).

h (Figure 6b). When Mozzarella cheeses were stored at $8^{\circ} \mathrm{C}$ (Figure $6 \mathrm{c}$ and $\mathrm{d}$ ), the time to appearance of blue coloration ranged from never (for cheeses stored at $8^{\circ} \mathrm{C}$, opened after $1 \mathrm{~h}$, and stored again at $8^{\circ} \mathrm{C}$ ) to $1 \mathrm{~h}$ (for cheeses stored at $8^{\circ} \mathrm{C}$, opened after $192 \mathrm{~h}$, and stored again at $20^{\circ} \mathrm{C}$ or at $8^{\circ} \mathrm{C}$; Figure $6 \mathrm{c}$ and $\mathrm{d}$ ).

\section{DISCUSSION}

Tables 1 and 2 show Pseudomonas fluorescens levels after intentional contamination of conditioning brine with 10 or $1,000 \mathrm{cfu} / \mathrm{mL}$. On d 1, significant differ- ences $(P<0.001)$ were observed between the 2 initial contamination levels only for Mozzarella cheeses stored at $8^{\circ} \mathrm{C}$ for all strains; on d 3 , differences were observed only for PSF ATCC; and on d 5, no differences were recorded for any strain at either storage temperature. These findings demonstrate that initial contamination of the $\mathrm{CB}$ with as little as $10 \mathrm{cfu} / \mathrm{mL}$ Pseudomonas spp. was sufficient to reach levels very close to or exceeding $10^{6} \mathrm{cfu} / \mathrm{mL}$ in products distributed to end users in the retail market. The fate of Pseudomonas fluorescens in Mozzarella cheeses followed the same trend with concentrations up to $10^{7} \mathrm{cfu} / \mathrm{g} 5 \mathrm{~d}$ after the 

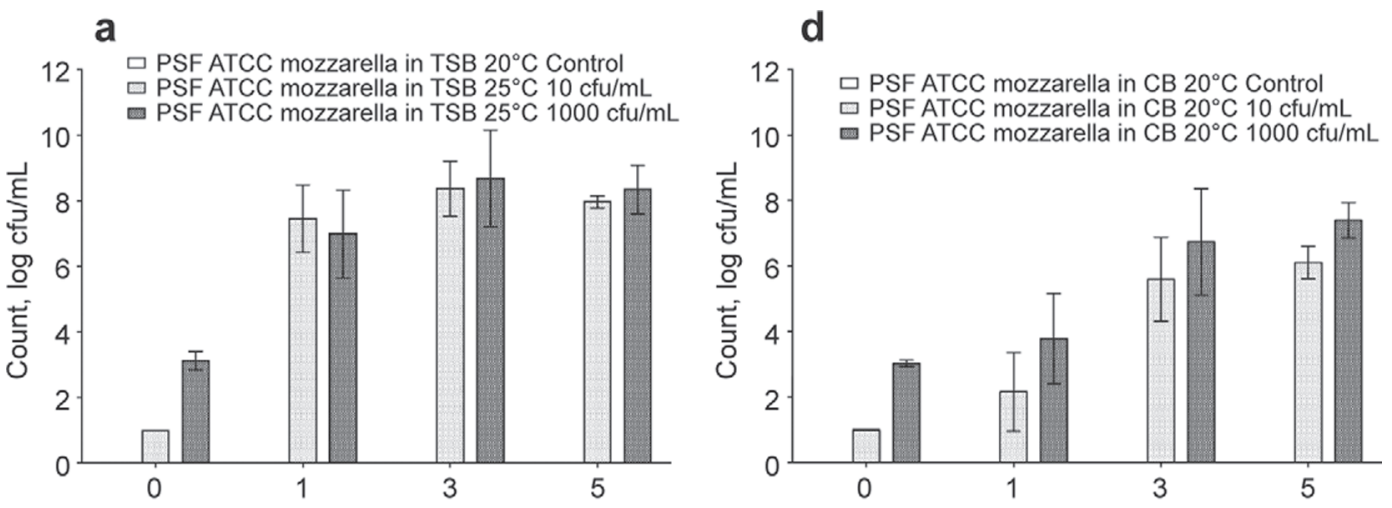

b
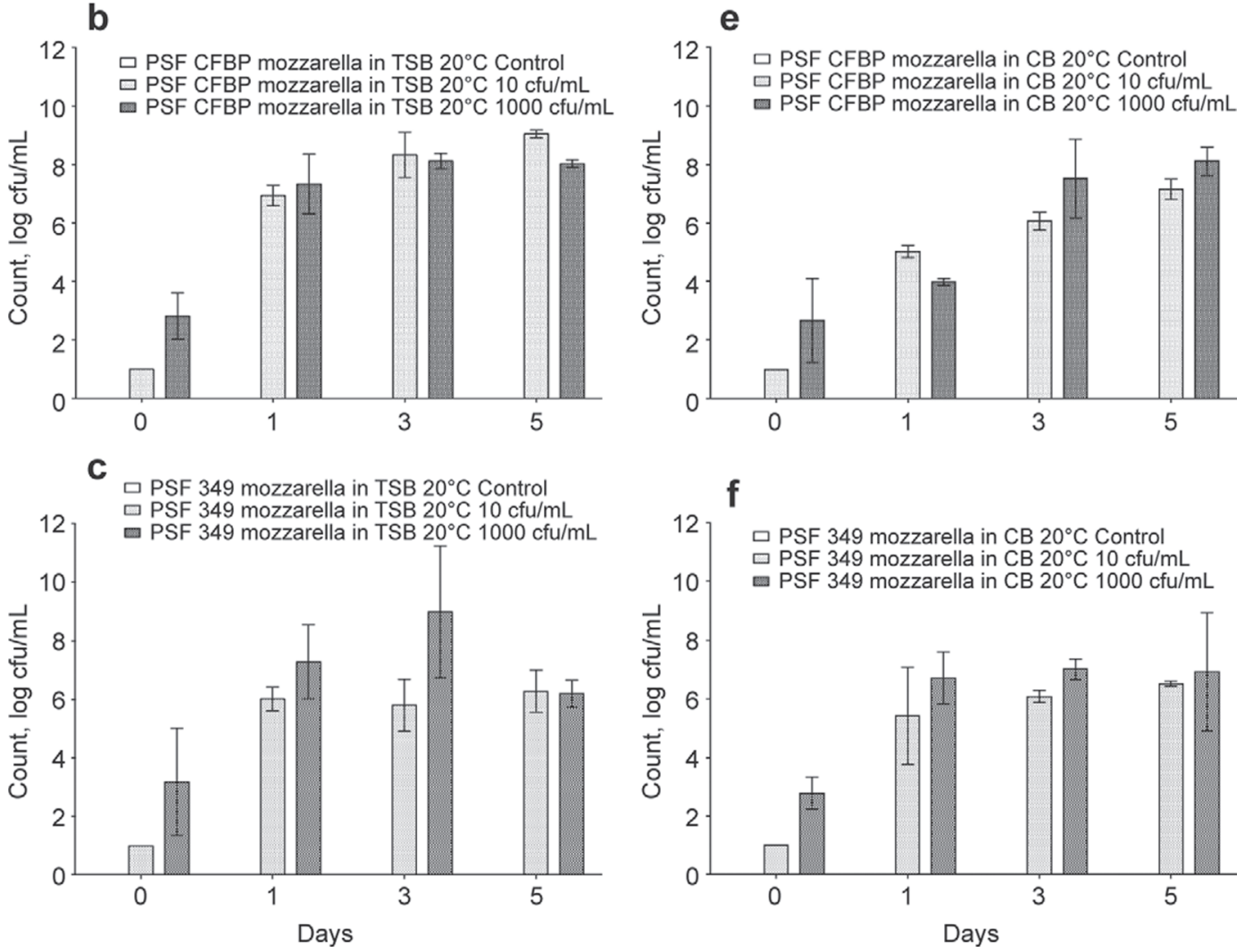

Figure 3. Evolution of Pseudomonas fluorescens strains ATCC 13525 (PSF ATCC), CFBP 3150 (PSF CFPB), and field strain 349 (PSF 349 ) in Mozzarella cheese placed in tryptic soy broth (TSB; panels a, b, and c) or conditioning brine (CB; panels d, e, and f) artificially contaminated with 10 or $1,000 \mathrm{cfu} / \mathrm{mL}$ and kept at $20^{\circ} \mathrm{C}$ (i.e., temperature abuse).

artificial contamination for the 2 faster-growing strains (PSF CFBP and PFS 349) and up to $5.66 \mathrm{log} \mathrm{cfu} / \mathrm{g}$ for the slower strain (PFS ATCC). For all strains, no significant differences were recorded $5 \mathrm{~d}$ after inoculation for cheeses stored at $8^{\circ} \mathrm{C}$. Control trials replacing the CB with TSB gave similar results, with no differences after $5 \mathrm{~d}$ of storage for the 2 initial levels of artificial contamination. With these findings, we concluded that initial contamination of $\mathrm{CB}$ with as little as $10 \mathrm{cfu} / \mathrm{mL}$ is sufficient to obtain a product with very high levels of
Pseudomonas spp., even if the cold chain is assured at temperatures close to $8^{\circ} \mathrm{C}$.

With this in mind, we observed traits of Mozzarella cheeses contaminated with the 3 strains of Pseudomonas fluorescens for up to $72 \mathrm{~h}$ after opening the packages. Packages contaminated with PSF ATCC strain and PSF CFBP, the latter being classified as biovar IV and as such, a potential producer of blue pigment, never showed the characteristic blue coloration. The field strain PSF 349, on the other hand, was able to cause 
a

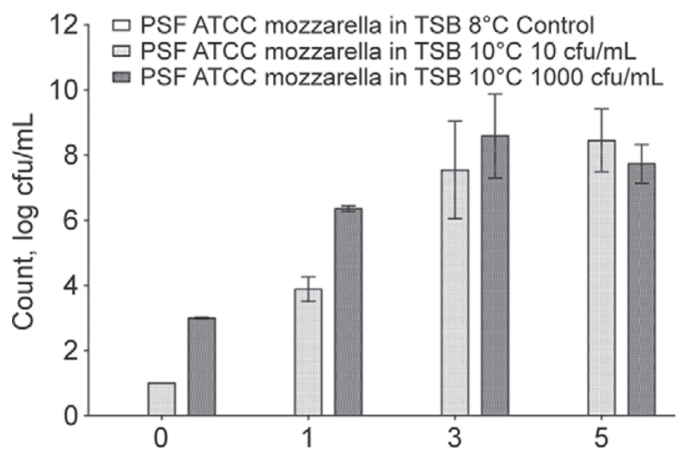

b

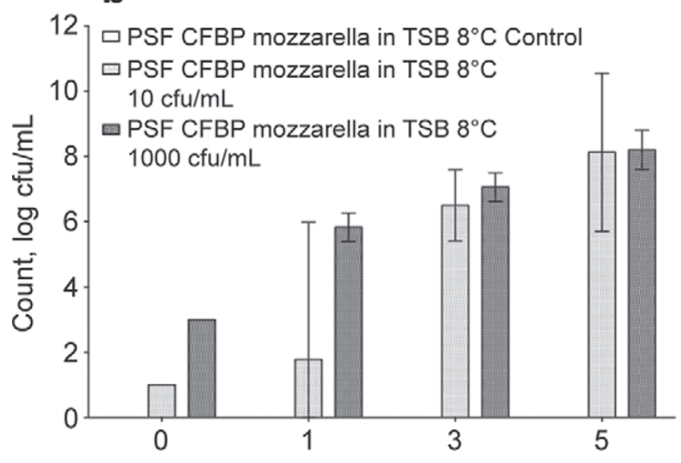

C

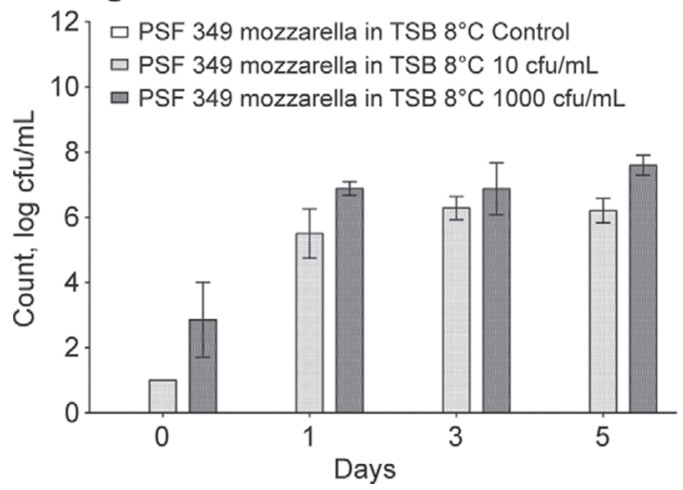

d

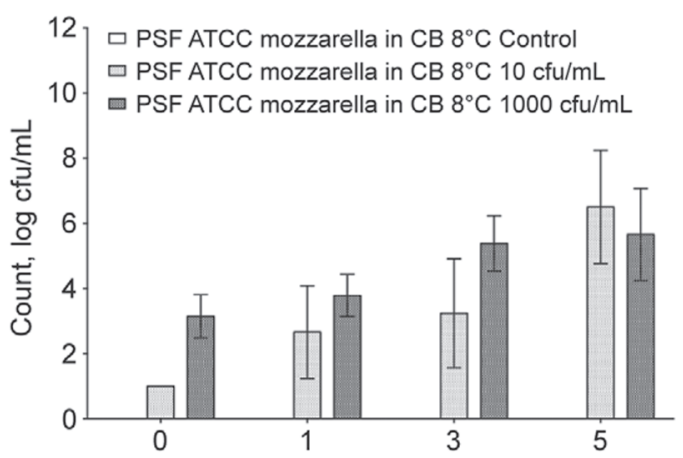

e

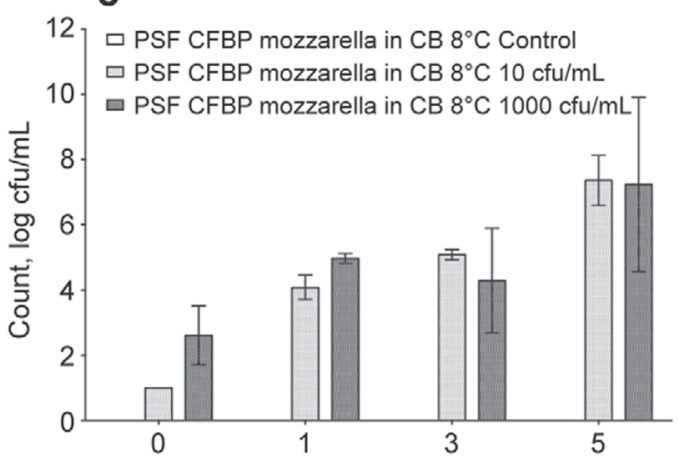

f

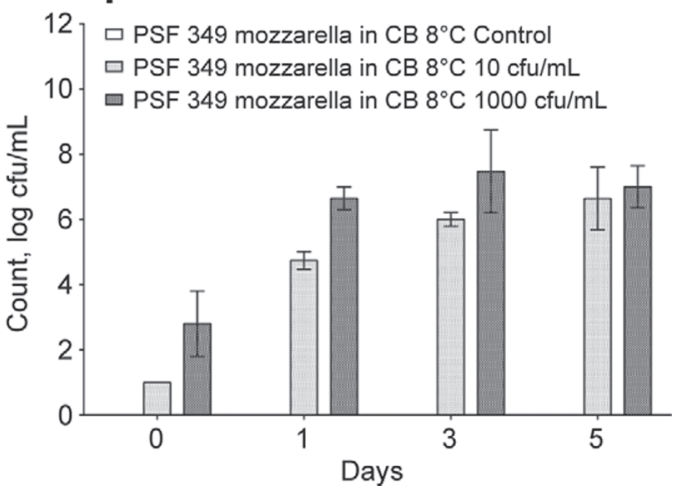

Figure 4. Evolution of Pseudomonas fluorescens strains ATCC 13525 (PSF ATCC), CFBP 3150 (PSF CFPB), and field strain 349 (PSF 349) in Mozzarella cheese placed in tryptic soy broth (TSB; panels a, b, and c) and conditioning brine (CB; panels d, e, and f) artificially contaminated with 10 or $1,000 \mathrm{cfu} / \mathrm{mL}$ and kept at $8^{\circ} \mathrm{C}$ (i.e., proper storage conditions).

the blue coloration, as shown in Figures 5 and 6 . In this experiment, we reproduced 4 temperature conditions from processing to final consumer: (1) spoilage temperature after production, throughout transportation to retail stores, and after consumer purchase; (2) spoilage temperature after production, throughout transportation to retail stores, followed by proper storage conditions by consumers; (3) proper storage temperature after production, throughout transportation to retail stores, followed by abuse conditions by consumers; and (4) proper storage temperature after production, throughout transportation to retail stores, and followed by proper storage conditions by consumers (Figure 5 for Mozzarella cheeses in CB and Figure 6 for control in TSB). We have demonstrated that for Mozzarella cheeses always stored at refrigeration temperature, even with an initial contamination level of $10 \mathrm{cfu} / \mathrm{mL}$, it is sufficient that consumers open the box and leave the Mozzarella cheese at room temperature (e.g., plated before consumption) or in the opened box (e.g., for further storage of leftover cheese) for the blue coloration to appear in from 1 to $48 \mathrm{~h}$. The longer the length of 

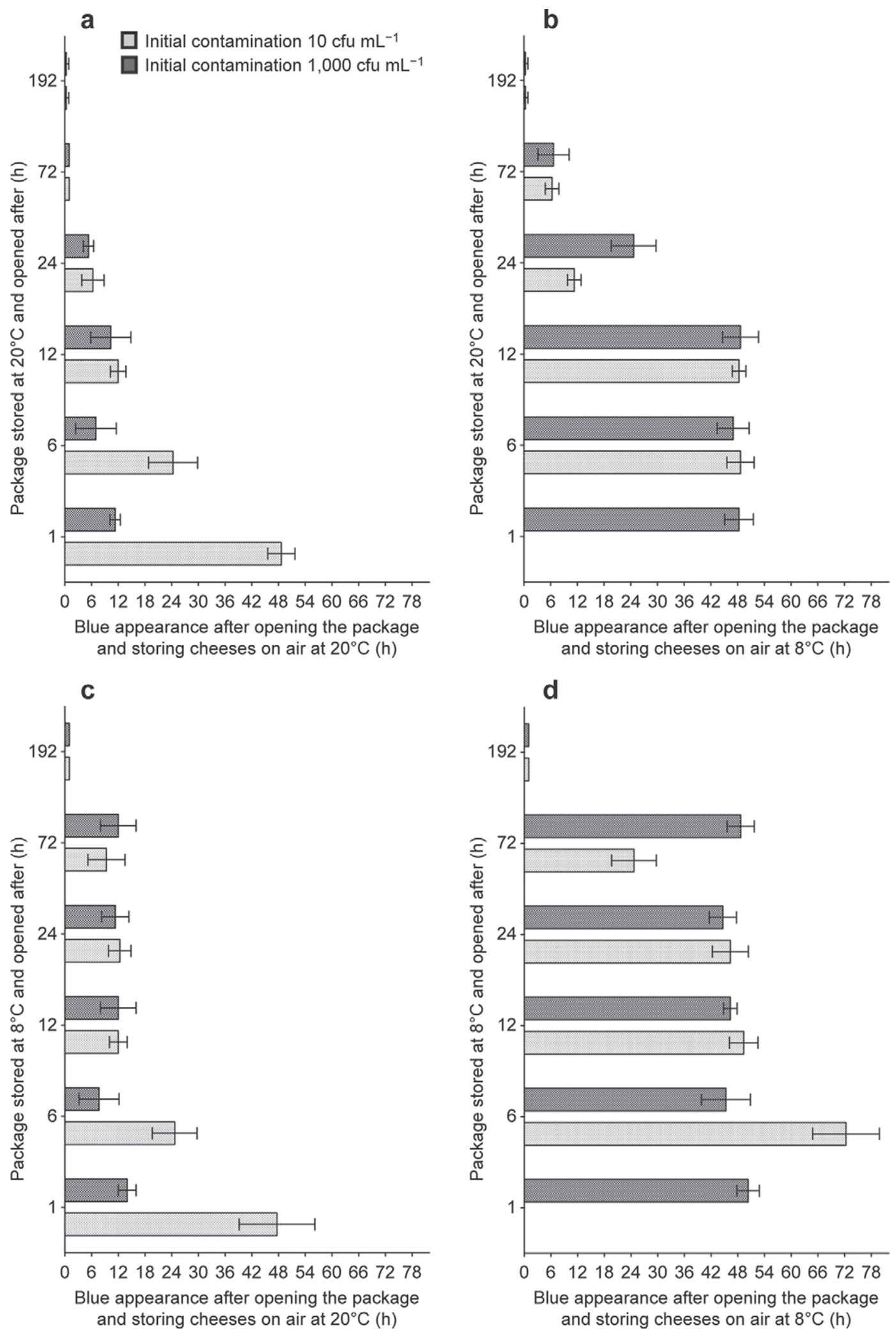

Figure 5. Timing of appearance of blue coloration after opening packages of Mozzarella cheese stored in tryptic soy broth contaminated with Pseudomonas fluorescens field strain (PSF 349). 

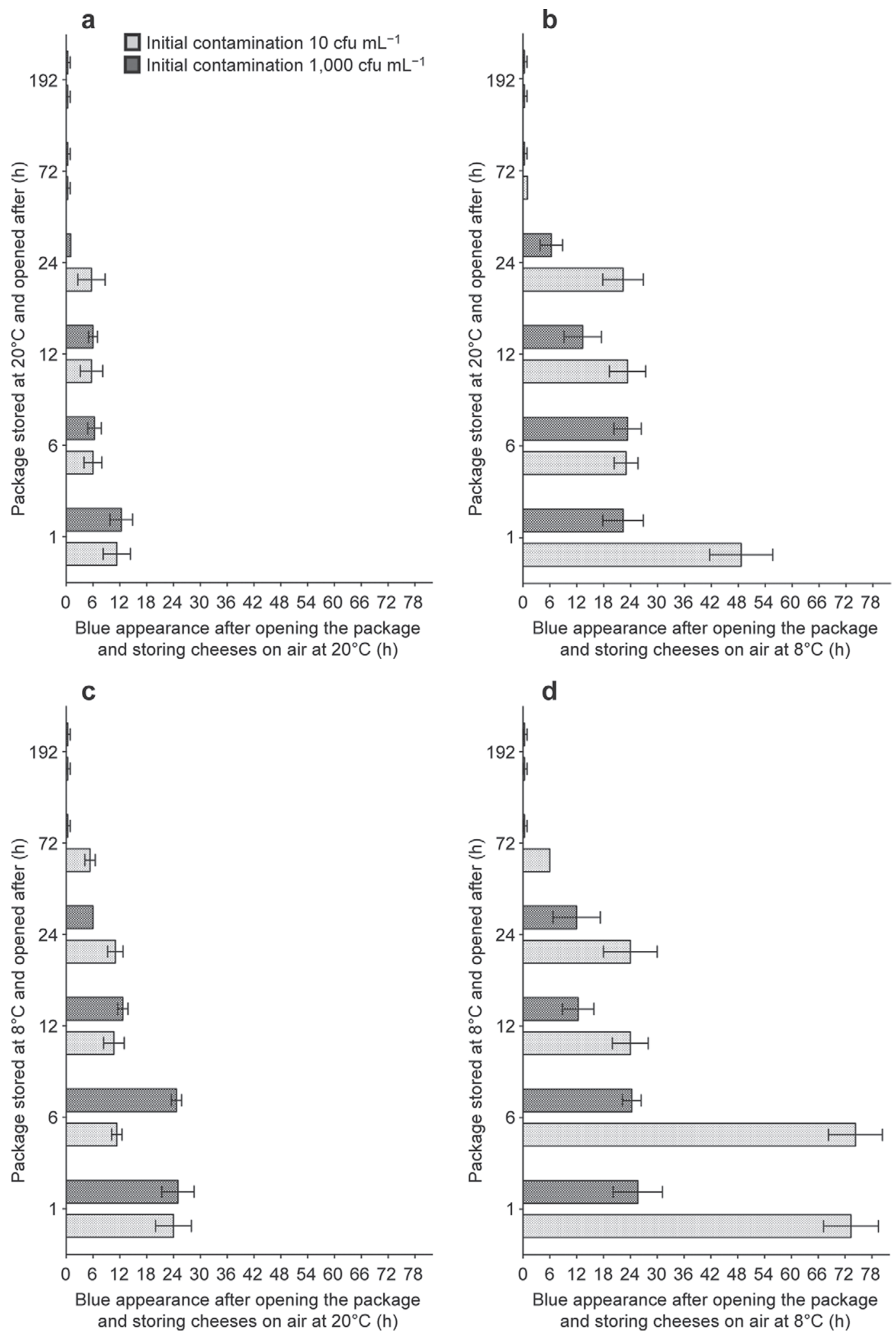

Figure 6. Timing of appearance of blue coloration after opening packages of Mozzarella cheese stored in conditioning brine contaminated with Pseudomonas fluorescens field strain (PSF 349). 
Table 1. Evolution of Pseudomonas fluorescens strains in conditioning brine (log cfu/mL; mean $\pm \mathrm{SE}$ ) at $20^{\circ} \mathrm{C}$ and $8^{\circ} \mathrm{C}$ after intentional contamination of conditioning brine with 10 or $1,000 \mathrm{cfu} / \mathrm{mL}$

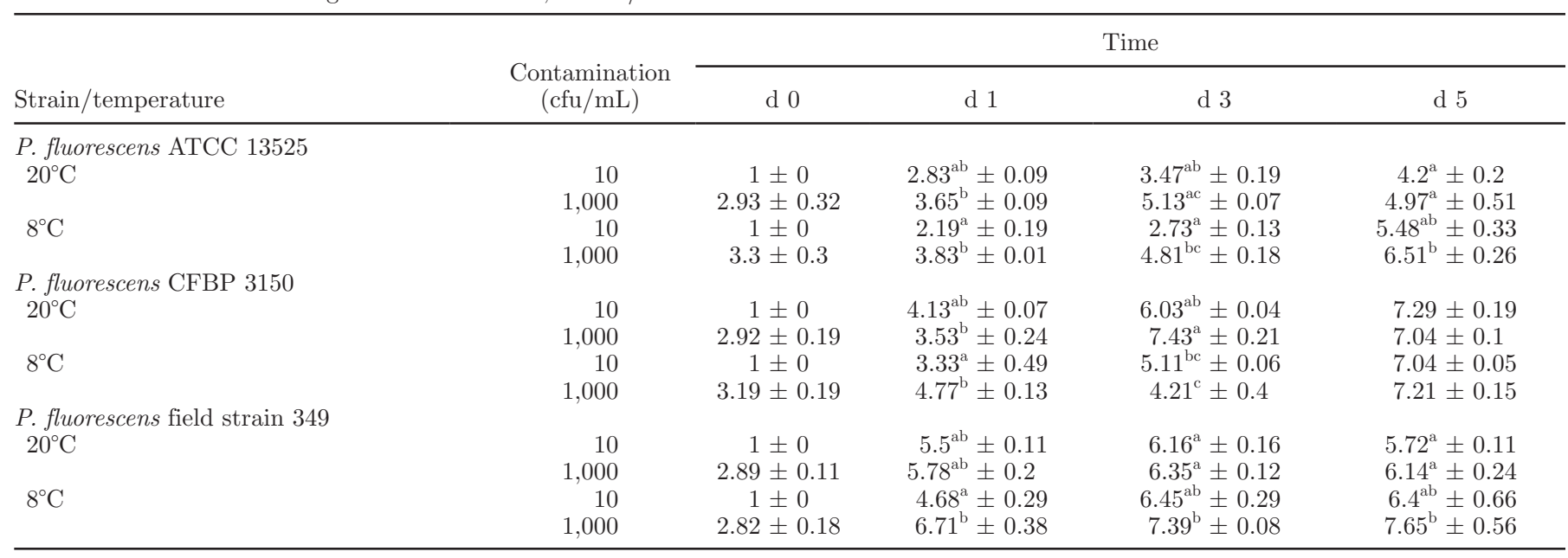

${ }^{\mathrm{a}-\mathrm{c}}$ Different superscript letters in the same column indicate statistically significant differences at $P<0.001$.

storage after production, the faster the appearance of blue coloring after the consumer opens the package. For packages stored under conditions of temperature abuse, the blue coloration was also apparent in the unopened box, but only after $8 \mathrm{~d}$ from production. For packages stored under refrigeration conditions and opened after $8 \mathrm{~d}$ from production, the blue coloration appeared less than $1 \mathrm{~h}$ after opening the package.

The observations in Figures 1 to 4, along with Figures 5 and 6, explain why it is not uncommon that in the same consignment of Mozzarella cheese, only a percentage of packages will show the defect, and why some cheeses do not show the defect at all, even with very high contamination levels of $P$. fluorescens. On the other hand, even when $\mathrm{CB}$ is contaminated with as little as $10 \mathrm{cfu} / \mathrm{mL}$, the blue coloration can appear, regardless of Mozzarella storage temperature.

This paper shed light on the actual storage conditions that cause the defect and on the evolution of Pseudomonas spp. in cheese and conditioning brine once contamination has occurred. Maintenance of the cold chain, of utmost importance for food safety, seems not to be an issue for Pseudomonas spp. contamination, given the ability of these microorganisms to grow well even at refrigeration temperatures. We demonstrated that, for P. fluorescens contamination of 10 or 1,000 $\mathrm{cfu} / \mathrm{mL}$, a storage temperature of $20^{\circ} \mathrm{C}$ is sufficient to provoke the blue defect within $12 \mathrm{~h}$ (in most cases, $<6$ $\mathrm{h}$; Figure 6a). With this in mind, we recommend that companies, in addition to microbiological analysis and

Table 2. Evolution of Pseudomonas fluorescens strains in Mozzarella cheese (log cfu/g; mean \pm SE) at $20^{\circ} \mathrm{C}$ and $8^{\circ} \mathrm{C}$ after intentional contamination of conditioning brine with 10 and $1,000 \mathrm{cfu} / \mathrm{mL}$

\begin{tabular}{|c|c|c|c|c|c|}
\hline Strain/temperature & $\begin{array}{l}\text { Contamination } \\
(\mathrm{cfu} / \mathrm{mL})\end{array}$ & \multicolumn{4}{|c|}{ Time } \\
\hline $20^{\circ} \mathrm{C}$ & 1,000 & $3.02 \pm 0.02$ & $3.78^{\mathrm{b}} \pm 0.32$ & $6.73^{\mathrm{b}} \pm 0.38$ & $7.40^{\mathrm{a}} \pm 0.13$ \\
\hline \multirow[t]{2}{*}{$8^{\circ} \mathrm{C}$} & 10 & $1.00 \pm 0.00$ & $2.66^{\mathrm{a}} \pm 0.33$ & $3.24^{\mathrm{c}} \pm 0.39$ & $6.50^{\mathrm{ab}} \pm 0.40$ \\
\hline & 1,000 & $3.14 \pm 0.15$ & $3.78^{\mathrm{b}} \pm 0.15$ & $5.38^{\mathrm{a}} \pm 0.20$ & $5.66^{\mathrm{b}} \pm 0.33$ \\
\hline \multicolumn{6}{|c|}{ P. fluorescens CFBP 3150} \\
\hline $20^{\circ} \mathrm{C}$ & 1,000 & $2.67 \pm 0.33$ & $3.98^{\mathrm{a}} \pm 0.03$ & $7.52 \pm 0.31$ & $8.11 \pm 0.11$ \\
\hline \multirow{2}{*}{$8^{\circ} \mathrm{C}$} & 10 & $1.00 \pm 0.00$ & $4.08^{\mathrm{a}} \pm 0.09$ & $5.07^{\mathrm{ab}} \pm 0.04$ & $7.35 \pm 0.18$ \\
\hline & 1,000 & $2.61 \pm 0.21$ & $4.96^{\mathrm{b}} \pm 0.04$ & $4.29^{\mathrm{b}} \pm 0.37$ & $7.23 \pm 0.62$ \\
\hline \multicolumn{6}{|c|}{ P. fluorescens field strain 349} \\
\hline \multirow[t]{2}{*}{$20^{\circ} \mathrm{C}$} & 10 & $1.00 \pm 0.00$ & $5.43 \pm 0.38$ & $6.09^{\mathrm{a}} \pm 0.05$ & $6.53 \pm 0.02$ \\
\hline & 1,000 & $2.78 \pm 0.13$ & $6.72^{\mathrm{a}} \pm 0.21$ & $7.02^{\mathrm{ab}} \pm 0.08$ & $6.93 \pm 0.47$ \\
\hline $8^{\circ} \mathrm{C}$ & 10 & $1.00 \pm 0.00$ & $4.74 \pm 0.06$ & $6.00^{\mathrm{a}} \pm 0.05$ & $6.64 \pm 0.22$ \\
\hline
\end{tabular}

\footnotetext{
${ }^{\mathrm{a}-\mathrm{c}}$ Different superscript letters in the same column indicate statistically significant differences at $P<0.001$.
} 
a standard hazard analysis and critical control point (HACCP) plan, include an inexpensive and easy postprocessing test, such as the testing of post-processed containers included in standard HACCP as implemented in the canning industry. A good approach could be the incubation of several packages per batch at $20^{\circ} \mathrm{C}$ and $30^{\circ} \mathrm{C}$ for 6 to $12 \mathrm{~h}$ (or even $24 \mathrm{~h}$, if delivery can be postponed) and checking for blue coloring for 6 to $12 \mathrm{~h}$ after opening the packages, before releasing the whole batch.

\section{ACKNOWLEDGMENTS}

The authors express sincere appreciation to members of Polyglot (Perugia, Italy) for a careful reading and comments on the article. The findings and conclusions in this paper are those of the authors and do not necessarily represent the views of the University of Perugia. Within the framework of the dottorato di ricerca "Sanità animale, produzioni zootecniche e sicurezza degli alimenti-XXVIII Ciclo," this research was supported by grants from Fondazione Cassa di Risparmio di Perugia (Italy) and from the Ministero degli Affari Esteri, Direzione Generale per la Promozione e Cooperazione Culturale (Rome, Italy), Executive programme of scientific and technological co-operation between the Italian Republic and the Republic of South Africa, a significant bilateral project between the Facoltà di Medicina Veterinaria, Università degli Studi di Perugia (Italy) and the Faculty of Veterinary Medicine, University of Pretoria (South Africa).

\section{REFERENCES}

Adams, M. R., and M. O. Moss. 2000. Food Microbiology. Royal Society of Chemistry, Cambridge, UK.
Cantoni, C., E. Marchisio, and M. Galli. 2000. Causa della colorazione blu-verde delle mozzarelle. Indust. Aliment. 39:586-588.

Cantoni, C., S. Stella, B. Ripamonti, and R. Marchese. 2001. Pseudomonas fluorescens e alterazione di colore delle mozzarelle. Indust. Aliment. 40:33-35.

Cenci-Goga, B., F. Clementi, and E. Di Antonio. 1995. Behaviour of lactic and non lactic microflora during production and ripening of on-farm manufactured Pecorino cheese. Ann. Microbiol. $45: 219-235$

Cenci-Goga, B. T., P. Bystricky, F. Clementi, and E. Di Antonio. 1993. Technology of a typical ewe cheese: Evaluation of lactic and non-lactic microflora in Brindza production. FEMS Microbiol. Rev. 12:167.

Cenci Goga, B. T., R. Selvaggini, J. E. L. Corry, F. Aloisio, D. Miraglia, and A. Vizzani. 2002. Time/temperature recording with dataloggers and development of specific software for cumulative abuse measurement. Pages 794-795 in Proc. 48th International Congress of Meat Science and Technology (ICoMST), Rome, Italy. Elsevier, Amsterdam, the Netherlands.

Coppola, S. E. Parente, S. Dumontet, and A. La Peccerella. 1988 The microflora of natural whey cultures utilized as starter in the manufacture of Mozzarella cheese from water-buffalo milk. Lait $68: 295-310$.

Coppola, S., F. Villani, R. Coppola, and E. Parente. 1990. Comparison of different starter systems for water-buffalo Mozzarella cheese manufacture. Lait 70:411-423.

Diez, A. M., J. Björkroth, I. Jaime, and J. Rovira. 2009. Microbial, sensory and volatile changes during the anaerobic cold storage of morcilla de Burgos previously inoculated with Weissella viridescens and Leuconostoc mesenteroides. Int. J. Food Microbiol. 131:168-177.

King, E. O., M. K. Ward, and E. E. Raney. 1954. Two simple media for the demonstration of pyocyanin and fluorescein. J. Lab. Clin. Med. 44:301-307.

Kobayashi, H., Y. Nogi, and K. Horikoshi. 2007. New violet 3,3-bipyridyl pigment purified from deep-sea microorganism Shewanella violacea DSS12. Extremophiles 11:245-250.

Sechi, P., A. Vizzani, S. Scuota, A. Zicavo, S. Parmegiani, and B. Cenci Goga. 2011. Anomalous blue colouring of mozzarella cheese intentionally contaminated with pigment-producing strains of Pseudomonas fluorescens. Ital. J. Food Safety 1:81-84. 